\title{
Three-Dimensional Identification of the Black Sea Mesoscale Eddies according to NEMO Numerical Model Calculations
}

\author{
A. A. Kubryakov*, A. I. Mizyuk, O. S. Puzina, M. V. Senderov \\ Marine Hydrophysical Institute, Russian Academy of Sciences, Sevastopol, Russian Federation \\ *e-mail: arskubr@ya.ru
}

\begin{abstract}
A new method of three-dimensional identification of mesoscale eddies based on the results of the Black Sea hydrodynamics modeling is applied. It is based on identification of the closed streamlines in the velocity fields. This method and the data resulted from the NEMO calculations for 2005-2008 are used to identify more than 1000 mesoscale eddies in the basin. The results permit to define eddy characteristic trajectories, calculate spatial variability of their velocities and radii and frequency of detection of cyclones and anticyclones. The obtained results are in good agreement with the earlier published studies of the eddy characteristics derived from satellite and in situ data. The modeling results permit to investigate the features of vertical distribution of eddy characteristics. The eddies are most often detected in the $0-150$ m layer (the highest detection frequency $\mathrm{F}$ is within 20-50 m). In the $150-300 \mathrm{~m}$ layer this value is two times smaller, but still is substantial. Below 300 meters $F$ quickly decreases with depth. The analogous distribution is characteristic of the eddy radii and orbital velocity: the highest values are observed in the upper 0-150 m layer, and in the lower layers they sharply decrease with depth. The analysis of seasonal variability of the eddy characteristics shows that the anticyclonic dynamics intensifies in summer, whereas the cyclonic one - in winter, that is consistent with the previous studies. The developed method provides additional opportunities for investigating the features of the eddy generation and evolution in the Black Sea.
\end{abstract}

Keywords: mesoscale eddies, Black Sea, modeling, vertical structure, automatic identification.

Acknowledgements. The analysis of eddy characteristics and the development of method for threedimensional automatic identification of eddies was carried out with the financial support of RFBR grant 16-05-00714. Analysis of eddies seasonal variability was supported by RFBR grant 17-0541089. Numerical dynamics modeling was carried out with financial support the State Order No. 0827-2015-0001.

For citation: Kubryakov, A.A., Mizyuk, A.I., Puzina, O.S. and Senderov, M.V., 2018. ThreeDimensional Identification of the Black Sea Mesoscale Eddies according to NEMO Numerical Model Calculations. Physical Oceanography, [e-journal] 25(1), pp. 18-26. doi:10.22449/1573-160X-2018-1-18-26

DOI: $10.22449 / 1573-160 X-2018-1-18-26$

(C) 2018, A. A. Kubryakov, A. I. Mizyuk, O. S. Puzina, M. V. Senderov

(C) 2018, Physical Oceanography

Introduction. Mesoscale eddies play an important role in a circulation, water exchange, transport of heat, salt, nutrients and in a vertical mixing in the Black Sea [1-11]. The development of methods for automatic identification of eddies on the basis of altimetric measurements provided the possibility to obtain a great number of statistic data on eddy parameters in the ocean. In [6-8] these methods were used for studying the dynamic and geometric characteristics of the Black Sea eddies, their evolution during eddy lifetime [6], their seasonal and interannual variability and relation with large-scale currents [7,8].

In contrast to the satellite data, which provide information only about the processes on the sea surface, modern numerical models allow us to investigate the three-dimensional variability of the dynamic and thermohaline characteristics of mesoscale eddies. Numerical modeling data were used in a number of works [5, 
12-14] to study the formation, interaction and energy of the Black Sea eddies, as well as their impact on the horizontal transport in the basin. For obtaining qualitative results, in these studies the description of eddy characteristics by the data of numerical models was carried out visually. This made impossible the obtaining of large amount of statistical information and complicated the analysis of the Black Sea eddy dynamics.

The methods for automatic eddy identification applied when analyzing twodimensional velocity fields according to altimetry measurements can be developed for three-dimensional eddy identification on the basis of numerical modeling [15]. In the present work a procedure of eddy identification according to the results of NEMO (Nucleus for European Modelling of the Ocean) model calculations based on the selection of the closed streamlines in the velocity field [16] on each horizon of the model is applied. On the basis of calculations over 2005-2008 horizontal and vertical distributions of eddy characteristics in the Black Sea were studied and evolution of individual eddies in the basin was analyzed.

Description of the model. In the present study regional configuration of numerical model for the Black Sea basin from [17], obtained on the basis of NEMO model complex [18], was applied. It is based on the system of primitive hydrothermodynamic equations given in [18] in the Boussinesq approximation and hydrostatics. This regional configuration [17] is a closed basin of the Black Sea with $10 \mathrm{~km}$ spatial resolution. $35 \mathrm{z}$-horizons with improved resolution in the upper layer are set vertically. For nonlinear terms in the transport-diffusion equations a scheme with a flux correction is applied. Vertical turbulent mixing is calculated using Mellor - Yamada model [19]. To parameterize a horizontal turbulent exchange, a biharmonic operator with the coefficients of viscosity and diffusion of heat and salt equal to $-2 \cdot 10^{10}$ and $-10^{10} \mathrm{~m}^{4} / \mathrm{s}$, respectively, are used. The calculation was carried out for 2005-2008 period with 10 min time step. Initial conditions were prepared on the basis of the Black Sea hydrophysical field reanalysis performed by Marine Forecast Center of Marine Hydrophysical Institute of RAS (http://mis.bsmfc.net/). The data of regional reanalysis obtained according to the information from MM5 model [20] were taken as an atmospheric impact.

Description of automatic eddy identification procedure. The algorithm for three-dimensional automatic eddy identification is based on the "winding angle" method [16], used in [6] for studying the characteristics of the Black Sea eddies by the fields of surface geostrophic velocities obtained from altimeter data. The method is based in the selection of closed streamlines in a velocity field.

To identify an eddy in two-dimensional velocity field in a certain moment of time, a virtual particle is launched in each grid node. Its trajectory in a stationary velocity field is calculated by Euler method with step $d t$. At each step of algorithm total angle of particle deviation (winding angle) is calculated. When total angle exceeds $360^{\circ}$, the particle makes a circular trajectory, i. e. is located on a closed streamline. This means that corresponding grid node is situated in an eddy. The computation is carried out for a certain amount of time $T$, which is an upper boundary of particle rotation period in an eddy. In this case, a restriction is imposed on the maximum length of the particle $L$ trajectory corresponding to the maximum possible radius of the eddy.

PHYSICAL OCEANOGRAPHY VOL. 25，ISS. 1 (2018) 
The cluster of the adjacent grid nodes forms the areas of identified eddy. An example of selected clusters of particles with the winding angle value over $360^{\circ}$ for the velocity field at $20 \mathrm{~m}$ depth for 03.09.2007 is represented in Fig. 1, $a$.
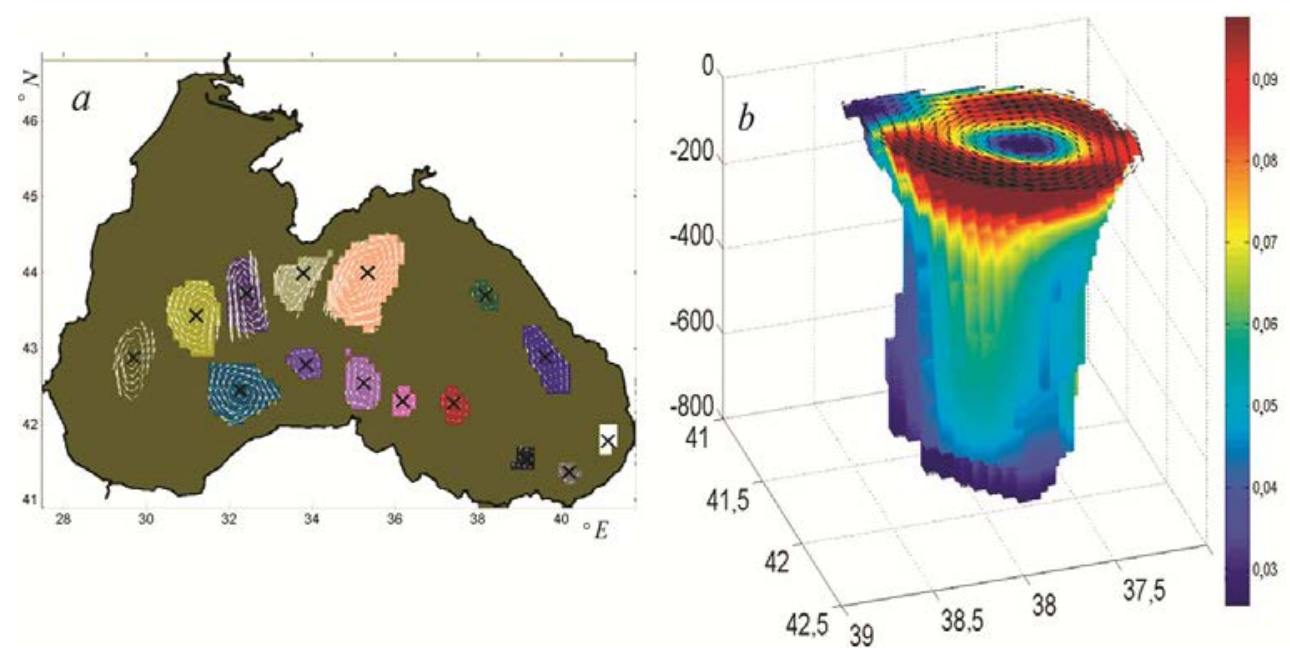

Fig. 1. Example of selected eddies on $20 \mathrm{~m}$ horizon for 03.09.2007 (a); identified three-dimensional eddy in the velocity field $(b)$

For each two-dimensional identified eddy we determined radius $R$ (by the area of an eddy), mean $v$ and maximum $v_{\max }$ orbital velocities and $W$ vorticity.

To determine three-dimensional characteristics of eddies by NEMO model data, «winding angle» eddy identification procedure was carried out on each model horizon. Further, the procedure of vertical eddy combining was performed. For this purpose a distance between the centers of two-dimensional eddies on the adjoining horizons was determined. If the mentioned distance did not exceed the mean radius of eddies on these horizons then the given two-dimensional eddies were combined into a three-dimensional one. The example of identified three-dimensional eddy in the velocity field is shown in Fig. 1, $b$.

After the selection of eddy formations the trajectories of individual eddy movement were determined. To do this, the distances between the eddy center for the present date and the centers of all eddies for the following moment of time were calculated. A pair of eddies with the minimum distance between them (which did not exceed a radius of an eddy) was considered as two consecutive positions of the same eddy.

Algorithm parameters can have significant impact on the obtained eddy characteristics: the maximum length of the particle trajectory $L=2 \pi R_{\max }\left(R_{\max }-\right.$ the maximum radius of an eddy) and the maximum rotation period of the particles $T=2 \pi R_{\max } / v_{\lim }$. Rotation period is related to the minimum mesoscale eddy vorticity which must be higher than the vorticity in large-scale closed circulations. $v_{\text {lim }}$ parameter corresponds to the minimum permissible orbital velocity at the periphery of large eddies with $R_{\max }$ radius, so that they are identified as mesoscale eddies and not as large-scale closed circulations. $R_{\max }$ and $v_{\lim }$ parameters are chosen on the basis of a comparison of identification results with the existing data on eddy 
dimensions and velocity in the Black Sea. At all horizons $R_{\max }$ was set as equal to $80 \mathrm{~km}$, which corresponds to the data on the maximum eddy dimensions in the Black Sea from [1-11]. $v_{\text {lim }}$ minimum velocity changed vertically. In the upper layers its value was taken as equal to $0.1 \mathrm{~m} / \mathrm{s}$ which corresponds to the weakest eddies in the basin. In the lower layers the velocity of eddies usually decays and for the layer under $200 \mathrm{~m} v_{\lim }$ was taken as equal to $0.02 \mathrm{~m} / \mathrm{s}$. Such value is approximately equal to the mean velocity of eddy movement in the Black Sea: $c=0.02-0.04 \mathrm{~m} / \mathrm{s}$ [6]. This corresponds to the value of nonlinearity parameter $P=v_{\lim } / c>1$, which is characteristic of nonlinear eddies that are able to transport a matter [21].

Trajectories and monitoring frequency of eddies. Trajectories of eddy formations with a lifetime of more than 90 days, calculated by the model data for 2005-2008, are shown in Fig. 2, a. Eddies in the Black Sea basin mainly move in a cyclonic direction along with the Black Sea Rim Current (BSRC) jet. This corresponds with the previous works [4-6]. According to the calculation data, the most long-lived eddies occur in the region of the Sevastopol anticyclone, the Caucasian coast, the Batumi anticyclone and near the central part of the Anatolian coast [5, 9]. In the northern part of the basin where the movement of eddies and the BSRC coincides with the direction of Rossby waves propagation (westwards), we observe more long-lived eddies than in the southern part where the eddies move eastwards. The same results were also obtained in [6] according to altimetry data.
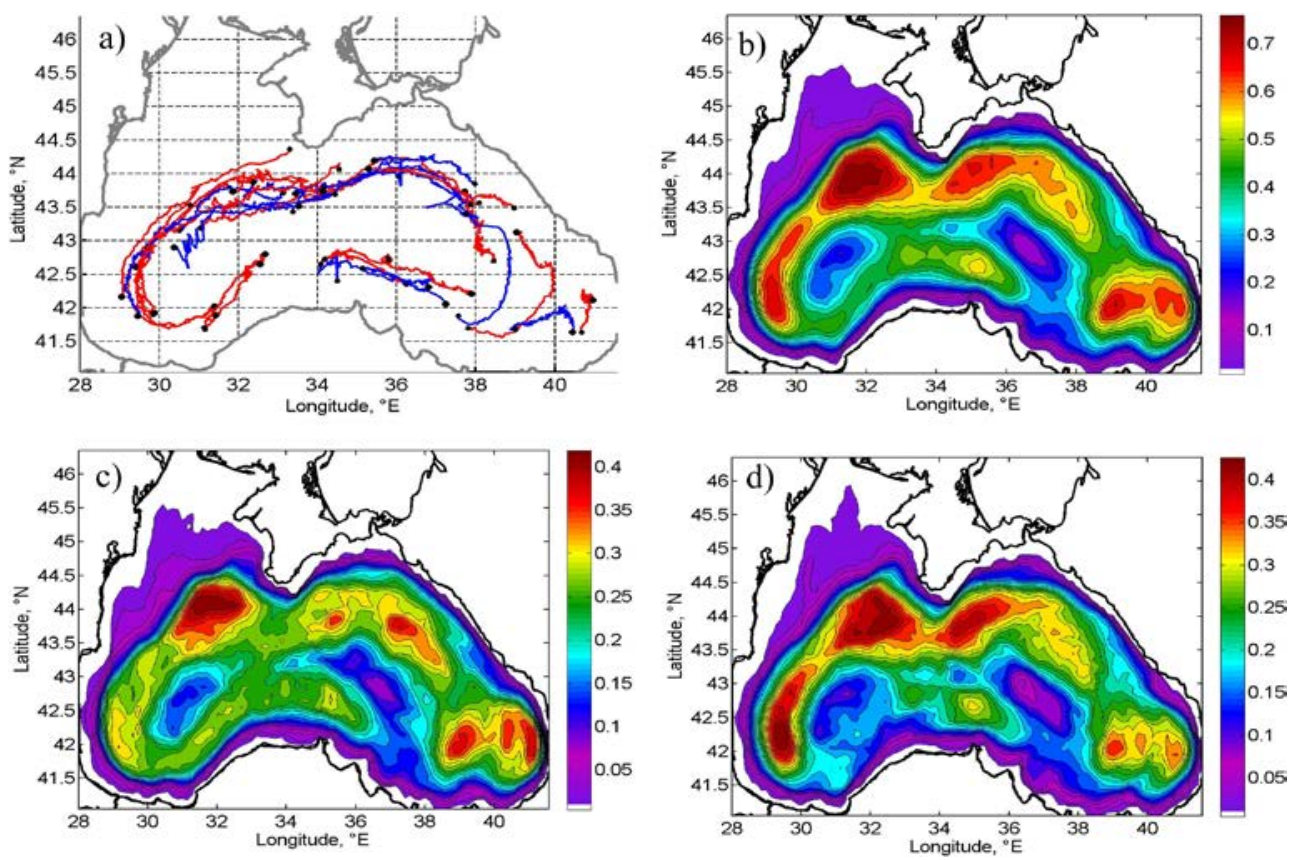

Fig. 2. Trajectories of eddy formations with more than 90 days lifetime (a) (red - anticyclones, blue cyclones); spatial distribution of eddy observation frequency in general $(b)$ and separatedly anticyclones $(c)$ and cyclones $(d)$ 
The maps of eddy observation probability at all depths (Fig. 2, $c, d$ ) show that in the continental slope area eddies are observed, on average, in 40-70\% of situations. Observation frequencies of cyclones and anticyclones are approximately equal, but there are some features of their spatial distribution. Most often anticyclonic eddies occur in the region of formation of the Sevastopol anticyclone ( $>40 \%$ of time) as well as in the one of the Batumi anticyclone in the southeastern part of the sea (30-40 \%) and the Caucasian gyre in the northeastern part of the sea (30-40\%). In these areas eddies slow down their motion, become quasistationary and, therefore, here they are observed for the greatest amount of time.

According to the model data, in the western part of the sea and eastwards from the Southern Coast of the Crimea the cyclones are observed more frequently (35$45 \%)$ than the anticyclones and somewhat less frequently in the areas of the Batumi anticyclone and the eastern coast. In the Sevastopol anticyclone area the probability of observing cyclones and anticyclones is almost equal.

The minima of eddy frequency of both signs are pointed out in the deep-water part of the sea - in centers of the eastern $\left(37^{\circ} \mathrm{W}, 43^{\circ} \mathrm{N}\right.$.) and the western $\left(31^{\circ} \mathrm{W}\right.$, $43^{\circ} \mathrm{N}$ ) cyclonic gyres.

Radius and orbital velocity of eddies. Time-averaged spatial distribution of the maximum (by depth) radius and the maximum orbital velocity of eddies is shown in Fig. 3. Mean radius of eddies is about $\sim 20-30 \mathrm{~km}$. It can be clearly seen from the maps that eddies in the southern part of the sea $(\sim 15-20 \mathrm{~km})$ are significantly smaller than in the rest of the basin $(\sim 25-30 \mathrm{~km})$. Such reduction of eddy radius is known from the satellite optical and altimetric measurements [5, 6, 22]. In the southern part of the water area the lowest orbital velocity of eddies is found. This fact is due to the features of wave motion interaction with topography in this zone and eastward eddy motion against the one of Rossby waves [22]. The modeling results successfully reproduce this feature of the Black Sea eddy dynamics.
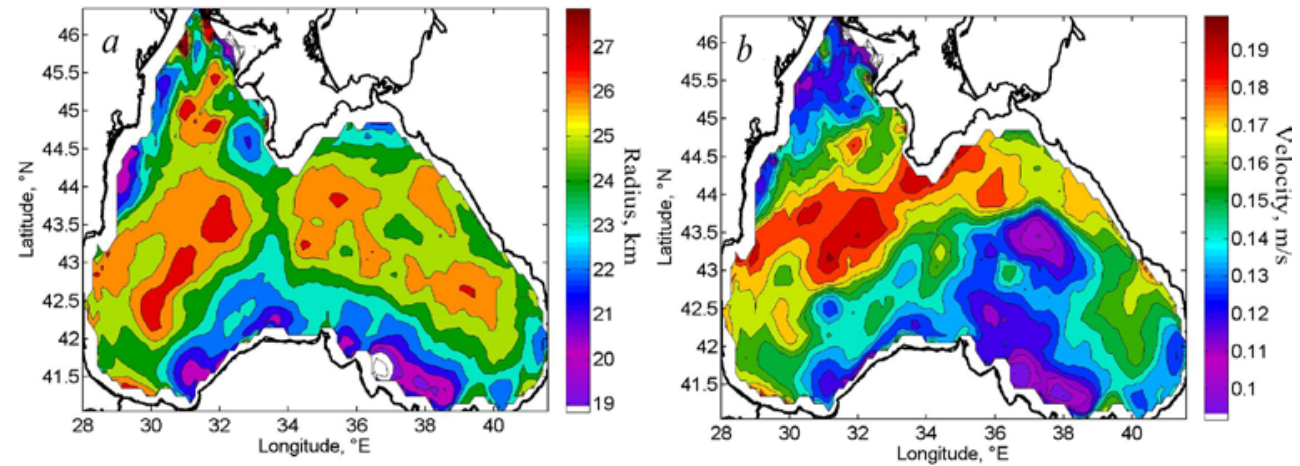

Fig. 3. Time-averaged spatial distribution of the maximum by depth radius (a) and the maximum orbital velocity $(b)$ of eddies

The minimum values of eddy radius and orbital velocities are also pointed out in the area of shallow northwestern shelf where small, short-lived and mainly barotropic eddies are usually observed. 
The largest values of radius ( 30-35 km) and orbital velocity are observed at the continental slope in the western part of the sea. Here the velocities, on average, exceed $0.2 \mathrm{~m} / \mathrm{s}$. In this part of the basin the passage of the Sevastopol anticyclone, formed from the western side of the Crimea, in the cyclonic direction is observed along with the jet of the BSRC. In the given model calculation it is the most intensive. Relatively high orbital velocities are also observed in the Batumi anticyclone region and at the narrow northeastern continental slope of the basin.

Vertical distribution of observation frequency, radius and orbital velocity of eddies. The number of eddies and the frequency of their observation significantly decrease in the lower layers of the basin (Fig. 4, a). Observation frequency of eddies $F$ was calculated as a time fraction of eddy observation in a certain calculated point. Then, in order to construct a graph in Fig. 4, $a$, the values were area-averaged on each model horizon. Three layers can be visually identified on the graph: the greatest $F$ values fall on the upper 0-150 m layer with the maximum at 30-40 m depths; then, down to $300 \mathrm{~m}$ depth $F$ values are almost constant and they are two times smaller than on the surface; below $300 \mathrm{~m}$ depth they begin to decrease down to zero. Similar variability is also characteristic of the radius for eddies (Fig. 5, b). The maximum sizes are observed on the basin surface (28$30 \mathrm{~km}$ ), below it the radius decreases down to $22 \mathrm{~km}$ value at $150 \mathrm{~m}$ depth. In 150$300 \mathrm{~m}$ layer the size of eddies remain practically constant and sharply decrease in the lower layers (below $300 \mathrm{~m}$ ).
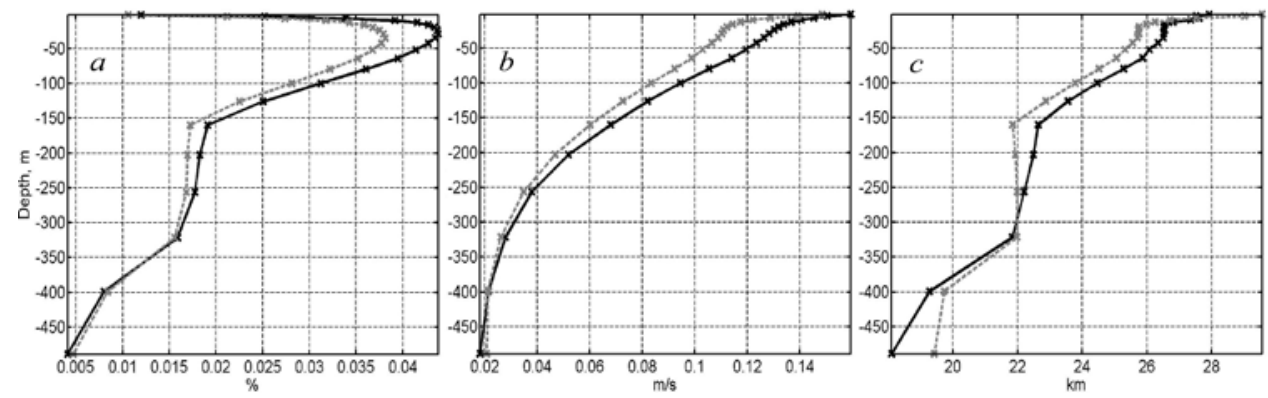

Fig. 4. Vertical distribution of observation frequency (a), mean orbital velocity $(b)$ and radius $(c)$ of anticyclones (black line) and cyclones (grey dashed line)
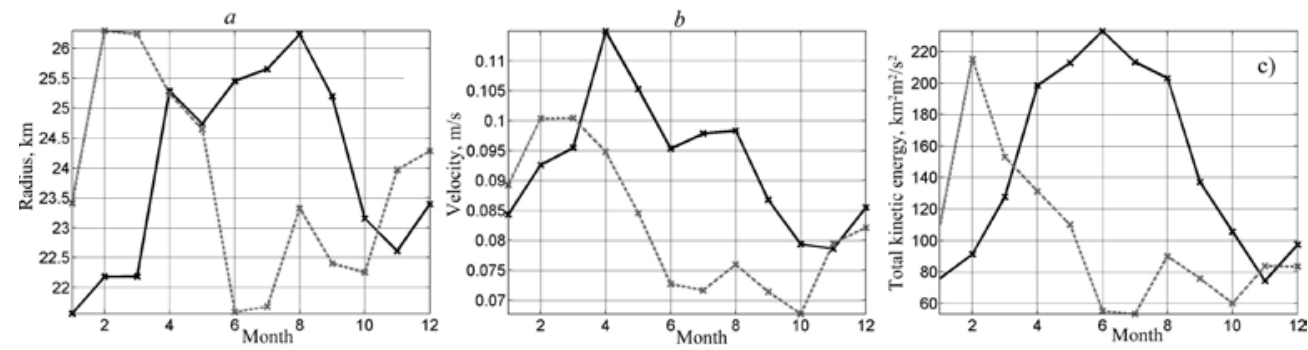

Fig. 5. Seasonal variability of radius $(\mathrm{km})$, the maximum orbital velocity $(\mathrm{m} / \mathrm{s})$ and total kinetic energy $\left(\mathrm{km}^{2} \cdot \mathrm{m}^{2} / \mathrm{s}^{2}\right)$ of anticyclones (black line) and cyclones (grey one) at $100 \mathrm{~m}$ depth

The maximum orbital velocity of eddies (see Fig. 2) is the highest on the surface where it is $0.15 \mathrm{~m} / \mathrm{s}$ for the anticyclonic and it is $0.13 \mathrm{~m} / \mathrm{s}$ for cyclonic PHYSICAL OCEANOGRAPHY VOL. 25, ISS. 1 (2018) 
eddies. Orbital velocity linearly decreases with depth down to $0.1 \mathrm{~m} / \mathrm{s}$ at $100 \mathrm{~m}$ horizon. It is about $0.05 \mathrm{~m} / \mathrm{s}$ at $200 \mathrm{~m}$ and $0.02 \mathrm{~m} / \mathrm{s}$ at $400 \mathrm{~m}$.

Seasonal variability. Graphs of seasonal variability of radius, orbital velocity and total kinetic energy ( $\left.E k=\sum_{i}^{N} S_{i} v_{i}=\sum_{i}^{N} \pi R_{i}^{2} v_{i}\right)$ at $100 \mathrm{~m}$ depth are shown in Fig. 5.

Seasonal variability of the main characteristics of cyclones and anticyclones is in antiphase. This was previously determined in [7] from altimeter data. Anticyclonic activity in the Black Sea increases in summer period during the decrease of the wind cyclonic vorticity and the BSRC intensity. The declining BSRC becomes unstable and breaks down forming a great amount of large anticyclones [23]. The BSRC energy turns into the one of anticyclonic formations. In April, when the BSRC is rather intensive, eddies formed as a results of its instability have the highest orbital velocity values. According to the model data, the maximum values of amount of anticyclones, their total kinetic energy and area covered by them are observed in June. From August - September anticyclone energy sharply decreases. It is characterized by the minimum values in November - February when the BSRC reaches the maximum of its intensity. At the same time, cyclonic activity is activated in February - March. The cyclones are formed mainly on the left from the BSRC, in the area of the maximum cyclonic shift of the current velocity. The velocity shift of currents is probably the main mechanism for their generation in winter period $[7,11]$.

Conclusion. A new method of three-dimensional automatic identification of the Black Sea mesoscale eddies from the numerical modeling data is proposed. It is based on identifying of closed streamlines in the velocity field at each computational horizon. This method was applied to analyze different geometric and kinematic characteristics of the Black Sea eddies, their spatial and temporal variability including their vertical distribution. The results obtained from NEMO model data coincide well with the data of satellite and hydrological studies. This represents high quality of the Black Sea eddy dynamics reproduction performed by the model. The presented method of three-dimensional identification allows us to study both statistic characteristics of great amount of eddies observed in the model and features of evolution of separated eddy formations. This provides deeper understanding of generation, evolution and dissipation mechanisms of eddies in the ocean.

\section{REFERENCES}

1. Ivanov, V.A. and Belokopytov, V.N., 2013. Oceanography of the Black Sea. Sevastopol: ECOSY-Gidrofizika, 210 p. (in Russian).

2. Krivosheya, V.G., Titov, V.B., Ovchinnikov, I. M., Kos'yan R.D and Skirta A.Y., 2000. The Influence of Circulation and Eddies on the Depth of the Upper Boundary of the Hydrogen Sulfide Zone and Ventilation of Aerobic Waters in the Black Sea. Oceanology, 40(6), pp. 767-776. 
3. Latun, V.S., 1990. Anticyclonic Eddies in the Black Sea in the Summer of 1984. Soviet Journal of Physical Oceanography, [e-journal] 1(4), pp. 279-286. https://doi.org/10.1007/BF021973974

4. Ginzburg, A.I., Kostianoy, A.G., Nezlin, N.P., Soloviev, D.M and Stanichny, S.V., 2002. Anticyclonic Eddies in the Northwestern Black Sea. Journal of Marine Systems, [e-journal] 32(1-3), pp. 91-106. https://doi.org/10.1016/S0924-7963(02)00035-0

5. Korotaev, G., Oguz, T., Nikiforov, A., Koblinsky, C., 2003. Seasonal, Interannual, and Mesoscale Variability of the Black Sea Upper Layer Circulation Derived from Altimeter Data. Journal of Geophysical Research, [e-journal] 108(C4), pp. 3122. https://www.doi.org/doi:10.1029/2002JC001508

6. Kubryakov, A.A. and Stanichny, S.V., 2015. Mesoscale Eddies in the Black Sea from Satellite Altimetry Data. Oceanology, [e-journal] 55(1), pp 56-67. https://doi.org/10.1134/S0001437015010105

7. Kubryakov, A.A. and Stanichny, S.V., 2015. Seasonal and Interannual Variability of the Black Sea Eddies and its Dependence on Characteristics of the Large-Scale Circulation. Deep-Sea Res. I., [e-journal] 97, pp. 80-91. https://doi.org/10.1016/j.dsr.2014.12.002

8. Kubryakov, A.A., Stanichny, S.V., Zatsepin, A.G. and Kremenetskiy, V.V., 2016. Long-term Variations of the Black Sea Dynamics and Their Impact on the Marine Ecosystem. J. Mar. Syst., [e-journal] 163, pp. 80-94. https://doi.org/10.1016/j.jmarsys.2016.06.006

9. Oguz, T., Latun, V.S., Latif, M.A., Vladimirov, V.V., Sur, H.I., Markov, A.A., Özsoy, E., Kotovshchikov, B.B., Eremeev, V.V. [et al], 1993. Circulation in the Surface and Intermediate Layers of the Black Sea. Deep-Sea Res. I, [e-journal] 40(8).pp. 1597-1612. https://doi.org/10.1016/0967-0637(93)90018-X

10. Shapiro, G.I., Stanichny, S.V. and Stanychna, R.R., 2010. Anatomy of Shelf-Deep Sea Exchanges by a Mesoscale Eddy in the North West Black Sea as Derived from Remotely Sensed data. Remote Sensing of Environment, [e-journal] 114(4), pp. 867-875. https://doi.org/10.1016/j.rse.2009.11.020

11. Zatsepin, A.G., Ginzburg, A.I., Kostianoy, A.G., Kremenetskiy, V.V., Krivosheya, V.G., Stanichny, S.V. and Poulain, P-M., 2003. Observations of Black Sea Mesoscale Eddies and Associated Horizontal Mixing. J. Geophys. Res., [e-journal] 108(C8), 3246. https://doi.org/doi:10.1029/2002JC001390

12. Staneva, J.V., Dietrich, D.E., Stanev, E.V. and Bowman, M.G., 2001. Rim Current and Coastal Eddy Mechanisms in an Eddy-Resolving Black Sea General Circulation Model. Journal of Marine Systems, [e-journal] 31(1-3), pp. 137-157. https://doi.org/10.1016/S09247963(01)00050-1

13. Demyshev, S.G. and Dymova, O.A., 2013. Numerical Analysis of the Mesoscale Features of Circulation in the Black Sea Coastal Zone. Izvestiya, Atmospheric and Oceanic Physics, [ejournal] 49(6), pp. 603-610. https://doi.org/10.1134/S0001433813060030

14. Lishaev, P.N., Korotaev, G.K., Knysh, V.V., Mizyuk, A.I. and Dymova, O.A., 2014. Vosstanovleniye Sinopticheskoy Izmenchivosti Gidrofizicheskikh Poley Chernogo Morya na Osnove Reanaliza za 1980-1993 Gody [Reproduction of Synoptic Variability of the Black Sea Hydrophysical Fields Based on Reanalysis for 1980-1993]. Morskoy Gidrofizicheskiy Journal, (5), pp. 49-68 (in Russian).

15. Lin, X., Dong, C., Chen, D., Liu, Y., Yang, J., Zou, B. and Guan, Y., 2015. ThreeDimensional Properties of Mesoscale Eddies in the South China Sea based on EddyResolving Model Output. Deep-Sea Res. I, [e-journal] 99, pp. 46-64. https://doi.org/10.1016/j.dsr.2015.01.007

16. Chaigneau, A., Gizolme, A. and Grados, C., 2008. Mesoscale Eddies off Peru in Altimeter Records: Identification Algorithms and Eddy Spatio-Temporal Patterns. Progress in Oceanogaphy, [e-journal] 79(2-4), pp. 106-119. https://doi.org/10.1016/j.pocean.2008.10.013

17. Madec, G., 2008. NEMO Ocean Engine. Note du Pôle de modélisation. Technical Report. France: Institut Pierre-Simon Laplace. No. 27. Available at: https://www.nemoocean.eu/doc/NEMO_book.html [Accessed: 11 December 2017]. 
18. Puzina, O.S. and Mizyuk, A.I., 2017. Vliyaniye Parametrov Vertikal'nogo Peremeshivaniya na Temperaturu Verkhnego Sloya Chernogo Morya [Influence of Vertical Mixing Parameters on the Temperature of the Upper Layer of the Black Sea]. In: IO RAS, 2017. Kompleksnyye Issledovaniya Mirovogo Okeana: Materialy II Vserossiyskoy Nauchnoy Konferentsii Molodykh Uchenykh [Complex Studies of the World Ocean: Materials of the II All-Russian Scientific Conference of Young Scientists] Moscow: IO RAS (in Russian).

19. Mellor, G.L. and Yamada, T., 1982. Development of a Turbulence Closure Model for Geophysical Fluid Problems. Rev. Geophys., [e-journal] 20(4), pp. 851-875. https://doi.org/10.1029/RG020i004p00851

20. Shokurov, M.V., 2011. Numerical Modeling of the Atmospheric Circulation over the Black Sea. In: MHI, 2011. Ekologicheskaya Bezopasnost' Pribrezhnoj i Shel'fovoj Zon i Kompleksnoe Ispol'zovanie Resursov Shel'fa [Ecological Safety of Coastal and Shelf Zones and Comprehensive Use of Shelf Resources]. Sevastopol: MHI NANU. Iss. 25, Vol. 2, pp. 91-113 (in Russian).

21. Chelton, D.B., Schlax, M.G. and Samelson, R.M., 2011. Global Observations of Nonlinear Mesoscale Eddies. Prog. Oceanogr., [e-journal] 91(2), pp. 167-216. https://doi.org/10.1016/j.pocean.2011.01.002

22. Blokhina, M.D. and Afanasyev, Y.D., 2003. Baroclinic Instability and Transient Features of Mesoscale Surface Circulation in the Black Sea: Laboratory Experiment. J. Geophys. Res., [e-journal] 108(C10), 3122. https://doi.org/10.1029/2003JC001979

23. Zatsepin, A.G., Denisov, E.S., Emelyanov, S.V. and Stanichny, S.V., 2005. Effect of bottom slope and wind on the near-shore current in a rotating stratified fluid: laboratory modeling for the Black Sea. Oceanology, 45(l), pp. S13-S26.

\section{About the authors:}

Arseniy A. Kubryakov - Senior Research Associate, Remote Sensing Department, FSBSI MHI (Sevastopol, Russian Federation), Ph.D. (Phys.-Math.), ORCID ID: 0000-0003-3561-5913, arskubr@mhi-ras.ru.

Artem I. Mizyuk - Research Associate, Department of the Oceanic Processes Dynamics, FSBSI MHI (Sevastopol, Russian Federation), PhD (Phys.-Math.), ORCID ID: 0000-0003-4885354X, artem.mizyuk@mhi-ras.ru.

Oksana S. Puzina - Senior Engineer-Researcher, Department of the Oceanic Processes Dynamics, FSBSI MHI (Sevastopol, Russian Federation), ORCID ID: 0000-0002-1637-4475, oksana_puzina@mhi-ras.ru.

Maksim V. Senderov - Senior Engineer-Researcher, Department of the Oceanic Processes Dynamics, FSBSI MHI (Sevastopol, Russian Federation), ORCID ID: 0000-0002-1025-590X, maxim.senderov@mhi-ras.ru.

\section{Contribution of the co-authors:}

Arseniy A. Kubryakov - general scientific supervision of the research, the development of methodology and carrying out the experimental research, preparation of the initial version of the text.

Artem I. Mizyuk - scientific supervision of the research, discussion of the study results.

Oksana S. Puzina - adjustment of mathematical model and carrying out the calculations, solution of organizational and technical issues on the text preparation.

Maksim V. Senderov - qualitative and quantitative analysis of the results.

All authors have read and approved the final manuscript.

The authors declare that they have no conflict of interest. 